\title{
TU/e EmonOWEN

\section{Application of frequency domain analysis to fault transients in complex HV transmission lines}

\section{Citation for published version (APA):}

Wu, L., Wouters, P. A. A. F., \& Steennis, E. F. (2013). Application of frequency domain analysis to fault transients in complex HV transmission lines. In 8th International Symposium on Advanced Topics in Electrical Engineering (ATEE 2013), May 23-25 2013, Bucharest (pp. 1-6).

\section{Document status and date:}

Published: 01/01/2013

\section{Document Version:}

Publisher's PDF, also known as Version of Record (includes final page, issue and volume numbers)

\section{Please check the document version of this publication:}

- A submitted manuscript is the version of the article upon submission and before peer-review. There can be important differences between the submitted version and the official published version of record. People interested in the research are advised to contact the author for the final version of the publication, or visit the $\mathrm{DOI}$ to the publisher's website.

- The final author version and the galley proof are versions of the publication after peer review.

- The final published version features the final layout of the paper including the volume, issue and page numbers.

Link to publication

\section{General rights}

Copyright and moral rights for the publications made accessible in the public portal are retained by the authors and/or other copyright owners and it is a condition of accessing publications that users recognise and abide by the legal requirements associated with these rights.

- Users may download and print one copy of any publication from the public portal for the purpose of private study or research.

- You may not further distribute the material or use it for any profit-making activity or commercial gain

- You may freely distribute the URL identifying the publication in the public portal.

If the publication is distributed under the terms of Article 25fa of the Dutch Copyright Act, indicated by the "Taverne" license above, please follow below link for the End User Agreement:

www.tue.nl/taverne

Take down policy

If you believe that this document breaches copyright please contact us at:

openaccess@tue.nl

providing details and we will investigate your claim. 


\title{
Application of Frequency Domain Analysis to Fault Transients in Complex HV Transmission Lines
}

\author{
L. Wu ${ }^{1}$, Student Member IEEE, P. A. A. F. Wouters ${ }^{1}$, E. F. Steennis ${ }^{1,2}$ \\ ${ }^{1}$ Eindhoven University of Technology, P.O. Box 513, 5600 MB Eindhoven, the Netherlands \\ ${ }^{2}$ DNV KEMA, P.O. Box 9035, 6800 ET, Arnhem, the Netherlands \\ lei.wu@tue.nl,p.a.a.f.wouters@tue.nl, fred.steennis@dnvkema.com
}

\begin{abstract}
Transients upon faults can be analyzed by the timedomain approach adopted e.g. in available EMTP based software. When the connection becomes complex and the effect of circuit parameters must be systematically evaluated, the efficiency drops and simplifications are required to limit computation time. For a new connection (Randstad380) the complexity is related to the embedded mutually coupling cables ( 2 circuits, 2 cables per phase) and the use of cable joints over varying distances. This paper applies an alternative approach that analyzes transients upon faults in frequency domain. The modeling procedure is presented in detail and it is applied to the Randstad380 south-ring connection. Comparison is made with PSCAD/EMTDC modeling based on a simplified transmission line configuration, which is suitable for time-domain simulation. The results show that the presented method is able to effectively and accurately analyze fault transients.
\end{abstract}

Keywords: Frequency domain analysis, Power system faults, Power system transients, Transmission line matrix methods

\section{INTRODUCTION}

Fault, also called unwanted short circuit, occurs unexpectedly in HV transmission systems (overhead lines or cables), and can have serious consequences like damage of expensive devices [1], [2]. Therefore, fault analysis is one of the key topics in power system analysis. EMTP-theory based simulation tools are widely used to provide the waveform of transient voltages and currents. EMTP-theory has two key features: a) curve fitting method to solve the differential equation consists of system impedance and admittance matrices; b) difference equation representing differential equation to describe e.g. the relationship of the voltage and current of each element, and its result is calculated and accumulated for each time step, [3], [4]. This method provides reliable results, but becomes rather inefficient when dealing with complex transmission lines, mainly because a) the fitting parameters are difficult to determine when a large number of conductors are mutually coupled; b) the simulation time steps have to be taken small when the length of line segment is small. In order to incorporate the time needed by a traveling wave travel through this segment (e.g. $0.5 \mu$ s for a length of $0.9 \mathrm{~km}$ for the studied connection), and consequently, the total simulation duration is prolonged. This problem is even more severe when simulating faults occurring at steady state operation. The calculation process

This work was financially supported by TenneT TSO B.V. within the framework of the Randstad380 cable research project, Arnhem, the Netherlands. has to evolve to steady state condition first. Only after that the transients upon the fault can be analyzed, [3], [4].

An example of the complexity is the new double-circuit $380 \mathrm{kV}$ transmission line (20.8 km long) in the Randstad area in the Netherlands, currently being under construction. It is composed of overhead line (OHL1, $6.0 \mathrm{~km})$, cable $(10.8 \mathrm{~km})$, and OHL2 $(4.0 \mathrm{~km})$, see Fig. 1 . The cable part includes 12 mutually coupled power cables and the total cable length is divided into 12 minor sections with on average a length of $0.9 \mathrm{~km}$. Three successive minor sections are grouped as one major section. Within one major section two neighboring minor sections are connected via cross-bonding joint and two neighboring major sections are connected via straight through joint. Three different trench types are used to bury the cables, mainly differing in cable depth and distance between each cable pair. An efficient method to analyze the fault in this complex transmission line is demanded, especially for multiscenario study, e.g. systematic research to investigate effects by varying specific parameters. This paper adopts an alternative method that directly solves the differential equation of system impedance and admittance matrices (no curve fitting method) and constructs the waveform of transient voltages and currents via frequency domain (no simulation time steps). The calculation process starts from steady state operation (Section II). This concept is applied to analyze the no-load switching surge response for different HV overhead line and underground cable configurations by [5]; in this paper, it is applied to analyze the single phase-toground fault. Results are compared with PSCAD/EMTDC simulation based on a simplified cable configuration (Section III). Detailed information of the transmission line configuration is presented in the Appendix.

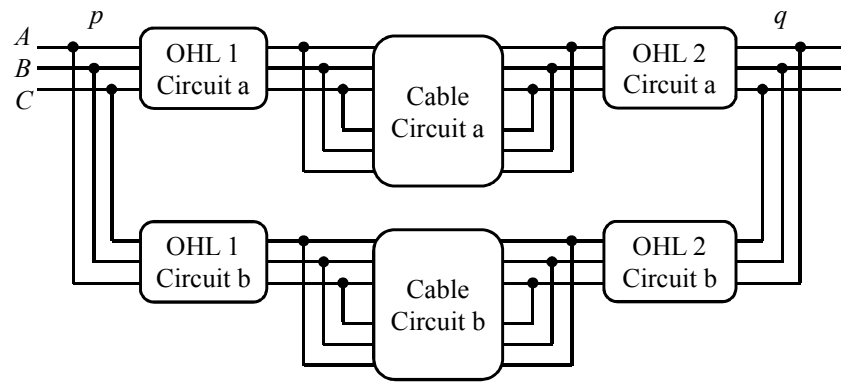

Fig. 1. Configuration of combined OHL and cable $380 \mathrm{kV}$ transmission system. 


\section{FAULT ANALYSIS IN FREQUENCY DOMAIN}

The core of the frequency domain analysis is the so-called ABCD-matrix built by frequency-dependent parameters, describing the relationship between the voltages and currents of two terminals of a component.

\section{A. ABCD-Matrix}

Consider the configuration shown in Fig. 2. The general result of establishing the ABCD-matrix of a transmission line ([5], [6]) is summarized in the Appendix. The complete ABCD-matrix of the transmission line shown in Fig. 1 (threephase system) can be obtained with the help of the modeling method for parallel connections given in [7], as

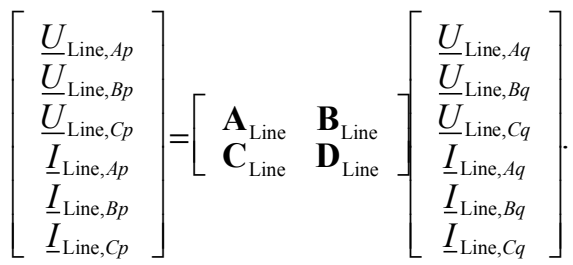

The ABCD-matrices of the circuit breaker equivalent resistor $\left(R_{\mathrm{CB}}\right)$ and source inductor $\left(L_{\mathrm{S}}\right)$ can be constructed as

$$
\left\lfloor\begin{array}{ll}
\mathbf{A}_{m} & \mathbf{B}_{m} \\
\mathbf{C}_{m} & \mathbf{D}_{m}
\end{array}\right\rfloor=\left[\begin{array}{cc}
\mathbf{I D} & \mathbf{Z}_{m} \\
\mathbf{O} & \mathbf{I D}
\end{array}\right]
$$

where $m$ presents $R_{\mathrm{CB}}$ or $L_{\mathrm{S}}$, and $\mathbf{Z}_{m}$ is a 3-by-3 diagonal matrix of $R_{\mathrm{CB}}$ or $\mathrm{j} \omega L_{\mathrm{S}}$. ID is an identity matrix and $\mathbf{O}$ is a zero matrix. Note that the circuit breaker is considered in the same manner as PSCAD/EMTDC, meaning a large resistor $\left(10^{9} \Omega\right)$ for open state and small resistor $\left(10^{-3} \Omega\right)$ for closed state. The ABCD-matrix of the system between locations $E$ and $H$ can be derived accordingly as

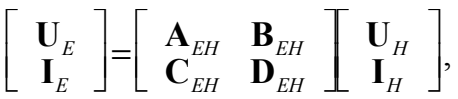

where

$$
\left.\left[\begin{array}{ll}
\mathbf{A}_{E H} & \mathbf{B}_{E H} \\
\mathbf{C}_{E H} & \mathbf{D}_{E H}
\end{array}\right]=\left[\begin{array}{ll}
\mathbf{A}_{L_{S}} & \mathbf{B}_{L_{S}} \\
\mathbf{C}_{L_{S}} & \mathbf{D}_{L_{S}}
\end{array}\right] \begin{array}{ll}
\mathbf{A}_{R_{\mathrm{CB}}} & \mathbf{B}_{R_{\mathrm{CB}}} \\
\mathbf{C}_{R_{\mathrm{CB}}} & \mathbf{D}_{R_{\mathrm{CB}}}
\end{array}\right]\left[\begin{array}{ll}
\mathbf{A}_{\text {Line }} & \mathbf{B}_{\text {Line }} \\
\mathbf{C}_{\text {Line }} & \mathbf{D}_{\text {Line }}
\end{array}\right] .
$$

Each of the voltage and current quantities represents threephase phasors, e.g. $\mathbf{U}_{E}$ and $\mathbf{I}_{E}$

$$
\mathbf{U}_{E}=\left[\begin{array}{lll}
\underline{U}_{E A} & \underline{U}_{E B} & \underline{U}_{E C}
\end{array}\right]^{\mathrm{T}}, \quad \mathbf{I}_{E}=\left[\begin{array}{lll}
\underline{I}_{E A} & \underline{I}_{E B} & \underline{I}_{E C}
\end{array}\right]^{\mathrm{T}} .
$$

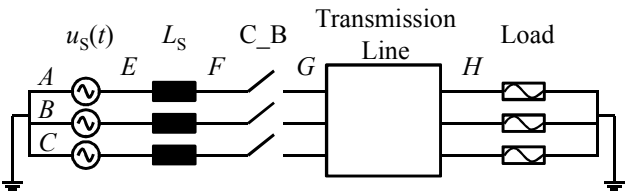

Fig. 2. Three-phase transmission system with source $u_{\mathrm{S}}(t)$, source equivalen inductor $L_{\mathrm{S}}$, circuit breaker C B, Transmission line, and Load. $E$ to $H$ indcate different locations.

\section{B. Fault Analysis with ABCD-Matrix}

Fault can basically be considered as the closure of a switch at the fault location. As proposed in [8], the closing or opening action of a switch can be regarded as adding an equivalent voltage or current source with equal amplitude and opposite sign to the voltage or current of the switch at the switching moment, such that afterwards the net voltage or current of the switch is zero.

Assume a single phase-to-ground fault with an arbitrary fault impedance occurs at location $H$ in phase $A$ (see Fig. 3) when $t=t_{\text {Fault }}$, and the circuit breaker contacts start to separate at $t=t_{\text {Separate. }}$ After the currents in the circuit breaker reach zero the circuit breaker opens at $t_{\text {Open }}$. The aim is to calculate the three-phase time-domain voltages and currents of both fault location and circuit breaker.

According to superposition principle, the general idea is to calculate the responses to voltage source and to each equivalent source to fault and opening action separately followed by their summation. With the presumption that the system is originally in steady state operation, the source voltage $\left(\boldsymbol{u}_{\text {Source }}(t)\right.$, in time domain) can be changed into phasors with power frequency $\left(\omega_{0}\right), \mathbf{U}_{E}\left(\omega_{0}\right)$. The time-domain voltage $\mathbf{u}_{H, \omega_{0}}(t)$ at location $H$ is calculated by inserting the load condition

$$
\mathbf{U}_{H}\left(\omega_{0}\right)=\mathbf{Z}_{\text {Load }}\left(\omega_{0}\right) \cdot \mathbf{I}_{H}\left(\omega_{0}\right),
$$

in (2), where $\mathbf{Z}_{\mathrm{Load}}$ is a diagonal matrix of $\underline{\mathbf{Z}}_{\mathrm{Load}, A}, \underline{\mathbf{Z}}_{\mathrm{Load}, B}$, and $\underline{Z}_{\mathrm{Load}, C}$. Next, the phasor is transformed to time-domain by

$$
\mathbf{u}_{H, \omega_{0}}(t)=\Re\left[\mathbf{U}_{H}\left(\omega_{0}\right) \mathrm{e}^{j \omega_{0} t}\right]
$$

where

$$
\mathbf{U}_{H}\left(\omega_{0}\right)=\left[\mathbf{A}_{E H}\left(\omega_{0}\right)+\mathbf{B}_{E H}\left(\omega_{0}\right) \cdot \mathbf{Z}_{\text {Load }}^{-1}\left(\omega_{0}\right)\right]^{-1} \cdot \mathbf{U}_{E}\left(\omega_{0}\right) .
$$

The corresponding load current at point $H$ is

$$
\mathbf{i}_{H, \omega_{0}}(t)=\mathfrak{R}\left[\mathbf{I}_{H}\left(\omega_{0}\right) \mathrm{e}^{j \omega_{0} t}\right],
$$

where

$$
\mathbf{I}_{H}\left(\omega_{0}\right)=\mathbf{Z}_{\text {Load }}^{-1}\left(\omega_{0}\right) \cdot \mathbf{U}_{H}\left(\omega_{0}\right) .
$$

With $\mathbf{U}_{H}$ and $\mathbf{I}_{H}$ known, the voltages and currents at any other location in the system can be obtained, e.g. at location $F$,

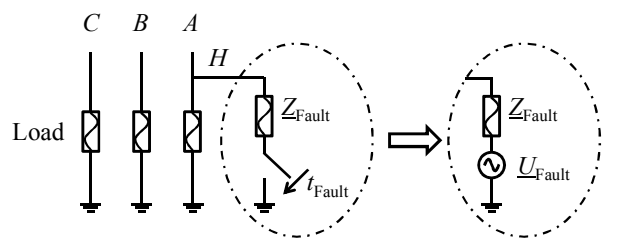

Fig. 3. Equivalent circuit diagram for fault with fault impedance in frequency domain. 


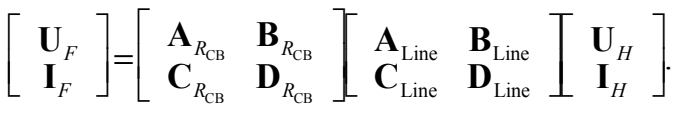

Thus, the voltages and currents at circuit breaker caused by the voltage source in steady state are:

$$
\mathbf{u}_{F G, \omega_{0}}(t)=\Re\left[\mathbf{U}_{F G}\left(\omega_{0}\right) \mathrm{e}^{j \omega_{0} t}\right], \quad \mathbf{i}_{F, \omega_{0}}(t)=\Re\left[\mathbf{I}_{F}\left(\omega_{0}\right) \mathrm{e}^{j \omega_{0} t}\right],
$$

where $\mathbf{U}_{F G}\left(\omega_{0}\right)=\mathbf{U}_{F}\left(\omega_{0}\right)-\mathbf{U}_{G}\left(\omega_{0}\right)$. From (4), the equivalent voltage source $u_{\text {Fault }}(t)$ representing the fault is

$$
u_{\text {Fault }}(t)=\left\{\begin{array}{cc}
0 & , \quad t<t_{\text {Fault }} \\
-u_{H A, \omega_{0}}(t), & t \geq t_{\text {Fault }}
\end{array} .\right.
$$

Applying Discrete Fourier Transformation to $u_{\text {Fault }}(t)$ produces $n$ phasors: $\underline{U}_{\text {Fault }}\left(\omega_{k}\right)(k=1, \ldots, n)$, each of which has its own response in the system that can be obtained individually according to Fig. 3. For each $\underline{U}_{H A}\left(\omega_{k}\right)$, applying similar procedure as for steady state calculation from (3) to (6), the corresponding voltages and currents of the circuit breaker $\left(\mathbf{u}_{F G, \omega_{k}, \text { Fault }}(t), \mathbf{i}_{F, \omega_{k}, \text { Fault }}(t)\right)$ and at the fault location $H$ $\left(\mathbf{u}_{H, \omega_{k} \text {, Fault }}(t), \mathbf{i}_{H, \omega_{k} \text {,Fault }}(t)\right)$ can be determined. The resulting transients after fault are:

$$
w_{M, \text { AfterFault }}(t)=w_{M, \omega_{0}}(t)+\sum_{k=1}^{n} w_{M, \omega_{k}, \text { Fault }}(t),
$$

where $w$ represents voltage $u$ or current $i$; and $M$ indicates the parameters at circuit-breaker $F G$, the near end $F$, or far end $H$ of the transmission line. After the circuit breaker detects the fault, it will open and the current will be interrupted at its natural zero-crossing moment. Since the currents in the threephase contacts of the circuit breaker reach zero point at different time instances, three equivalent current sources to the opening of the correlated phases have to be constructed in sequence. The decision for the first phase to open is made by checking in which phase the current of $i_{F, \text { AfterFault }}(t)$ obtained by (7) reaches zero in the first place after the physical separation of the circuit breaker contacts $\left(t_{\text {Separate }}\right)$, indicated by "1st" in the following subscript. The equivalent current source to the opening of this phase is

$$
i_{\text {Open, 1st }}(t)=\left\{\begin{array}{cll}
0 & , \quad t<t_{\text {Open,1st }} \\
-i_{F, \text { lst,Afferfault }}(t) & , \quad t \geq t_{\text {Open,1st }}
\end{array} .\right.
$$

The decision for the opening of the second phase has to combine the response (circuit breaker current) to $i_{\text {Open, st }}(t)$ with previous sources: $u_{\text {Source }}(t)$ and $u_{\text {Fault }}(t)$. Finally, the total transient voltages and currents can be obtained by summing all the individual responses to the corresponding sources.

\section{CASE STUDY}

The method of analyzing the fault transient in frequency domain described in Section II is applied to the system configuration shown in Fig. 1 (380 kV level and each circuit has a rated current of $4 \mathrm{kA}$ ). The scenario defining parameters are presented in Table I and the results are shown in Fig. 4. Transients start from $0.105 \mathrm{~s}$. The current in phase $A$ changes abruptly, and it distorts the voltages and currents in phase $B$ and $C$. After the contacts of the circuit breaker separate in sequence, the current in each phase extinguishes accordingly, immediately followed by the establishment of the voltages over the circuit breaker.

A comparison between this adopted method and PSCAD/EMDTC simulation based on the following simplification:

- 12 cable minor sections are identical: $0.9 \mathrm{~km}$ long, open trench, with earth resistivity as $100 \Omega \mathrm{m}$;

- two cable circuits are no longer mutually coupled.

The voltages and currents at the load (position $H$ in Fig. 2) are shown in Fig. 5a-c (left column) for all phases. Fig. 5d-f (right column) show the voltages over and currents through the circuit-breaker (position $F G$ in Fig. 2). In each graph, the two curves (from the adopted method and from PSCAD/EMTDC time-domain simulation) have almost equal profiles, validating the adopted method.

TABLE I

PARAMETERS FOR FAULT TRANSIENT ANALYSIS

\begin{tabular}{|c|c|c|c|}
\hline$\underline{U}_{\text {Source }}$ & 1 p.u. $(50 \mathrm{~Hz})$ & $L_{\mathrm{S}}$ & $10 \mathrm{mH}$ \\
\hline$R_{\text {Load }}$ & $55 \Omega(50 \%$ loaded $)$ & $t_{\text {Fault }}$ & $0.105 \mathrm{~s}$ \\
\hline$R_{\text {Fault }}$ & $5 \Omega([9])$ & $t_{\text {Separate }}$ & $0.11 \mathrm{~s}$ \\
\hline
\end{tabular}

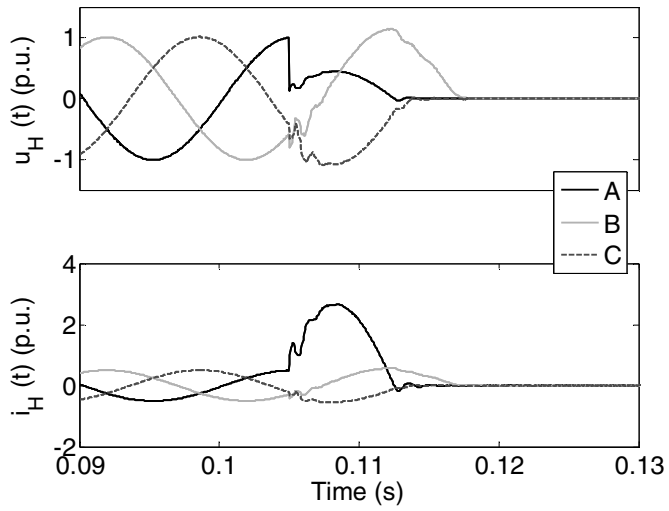

(a)
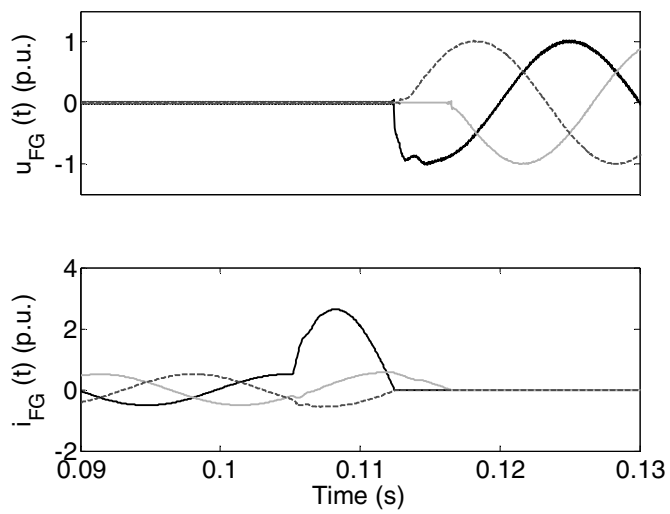

(b)

Fig. 4. Single-phase fault transient with complete configuration shown in Fig. 1: at load side of circuit (a), and at circuit breaker (b). 


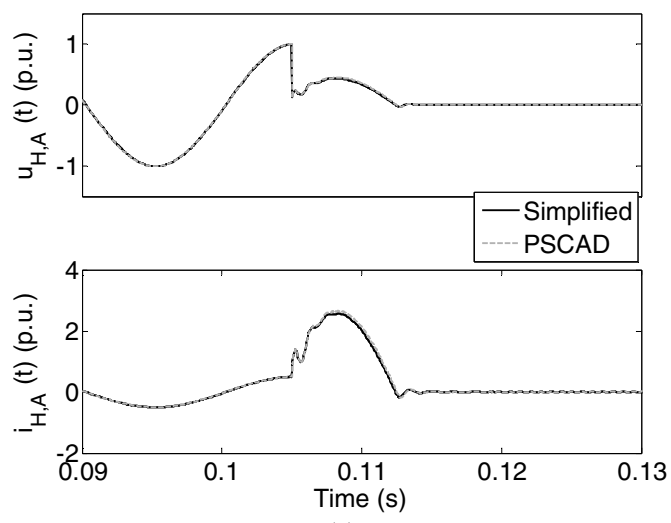

(a)
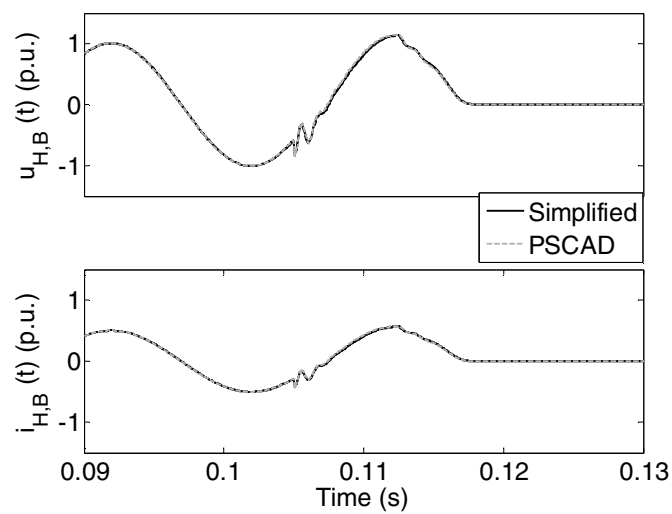

(b)

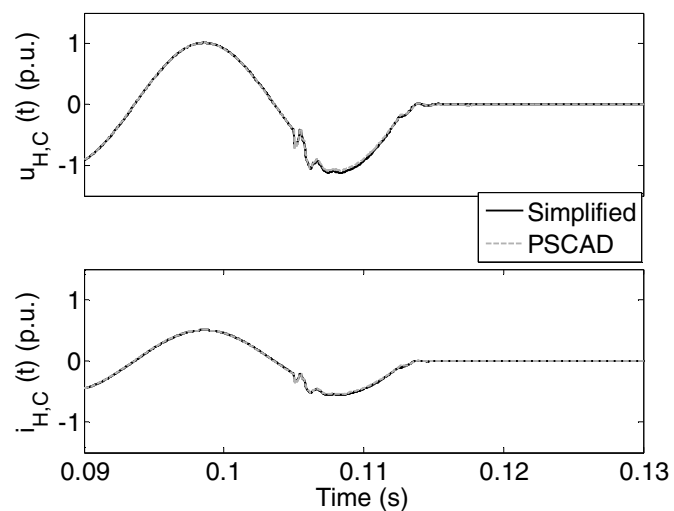

(c)

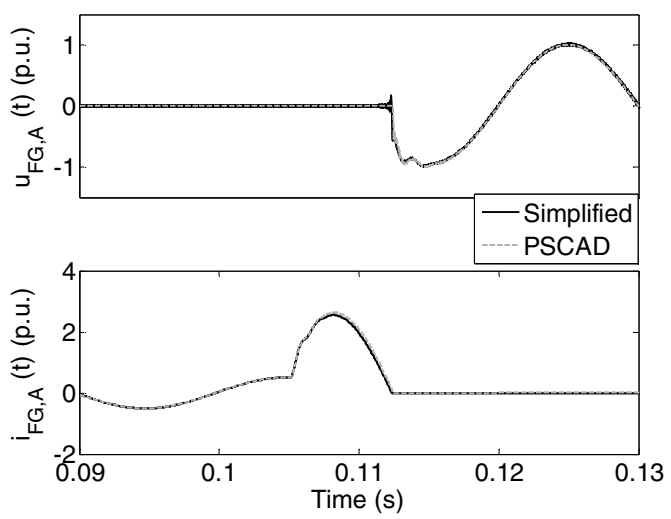

(d)
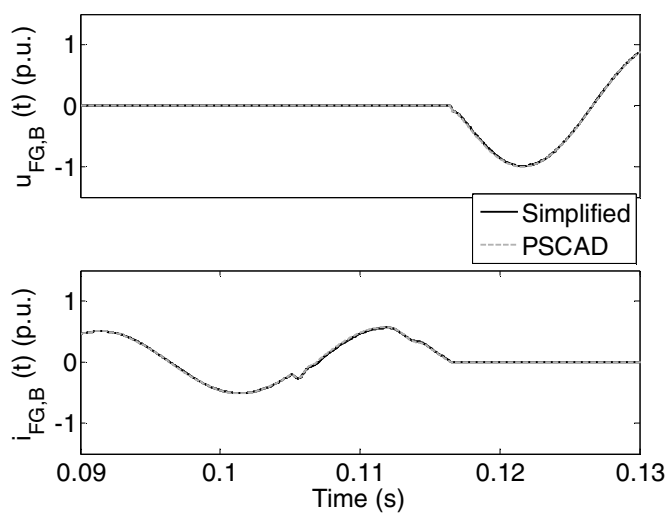

(e)

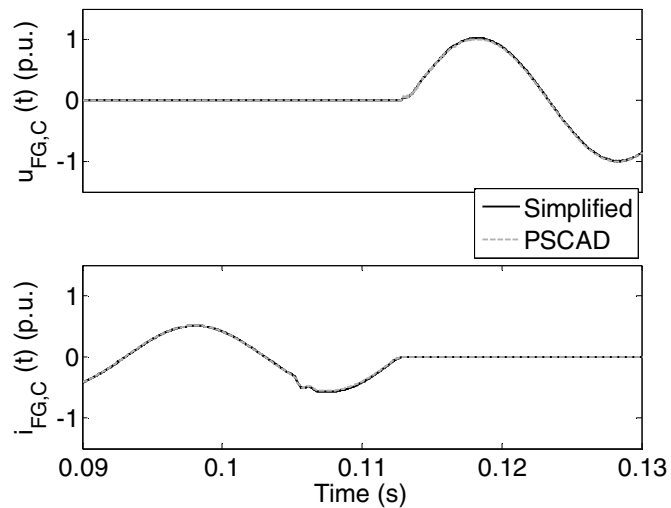

(f)

Fig. 5. Comparison with PSCAD/EMTDC simulation (voltages and currents in phase $A$ to $C$ ): of location $H$ (a) to (c); and of circuit breaker (d) to (f).

For the shown configuration, the adopted method (implemented by MATLAB code without optimizing for calculation speed [10]) is faster than PSCAD/EMTDC software by a factor of about 20 using the same platform.

\section{CONCLUSION}

This paper uses a frequency domain approach to analyze the fault transients in a transmission system (including overhead line and underground cable), which is too complex to efficiently analyze by EMTP-theory. A model of a series connection of an equivalent voltage source with impedance is used to represent the fault in frequency domain. With the applied method, transients can be depicted based on the complete model, and the comparison with PSCAD/EMTDC software based on a simplified model assures the accuracy of this method.

Furthermore, the equivalent model of the fault with fault impedance can be applied to model nonlinearity phenomena in transmission system in frequency domain, e.g. surge arrester, since they share the same mathematical concepts.

\section{APPENDIX}

Fig. 6 depicts a single-line representation of arbitrary number of conductors, whose distributed parameters indicated by impedance $\mathbf{Z}$ and admittance $\mathbf{Y}$ are assembled in

$$
-\frac{\mathrm{d}}{\mathrm{d} x} \mathbf{U}=\mathbf{Z} \cdot \mathbf{I}, \quad-\frac{\mathrm{d}}{\mathrm{d} x} \mathbf{I}=\mathbf{Y} \cdot \mathbf{U} .
$$




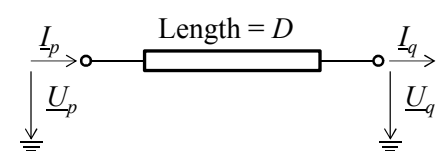

Fig. 6. Illustration of ABCD-matrix for a single line.

The method used in this paper directly solves (9) into the form of ABCD-matrix relating terminals $p$ and $q$.

$$
\left[\begin{array}{l}
\mathbf{U}_{p} \\
\mathbf{I}_{p}
\end{array}\right]=\left[\begin{array}{ll}
\mathbf{A} & \mathbf{B} \\
\mathbf{C} & \mathbf{D}
\end{array}\right]\left[\begin{array}{l}
\mathbf{U}_{q} \\
\mathbf{I}_{q}
\end{array}\right],
$$

where

$$
\left[\begin{array}{ll}
\mathbf{A} & \mathbf{B} \\
\mathbf{C} & \mathbf{D}
\end{array}\right]=\left(\mathbf{T} \mathrm{e}^{\Lambda D} \mathbf{T}^{-1}\right)^{-1}
$$

The columns of matrix $\mathbf{T}$ are the eigenvectors of

$$
\left[\begin{array}{cc}
\mathbf{O} & -\mathbf{Z} \\
-\mathbf{Y} & \mathbf{O}
\end{array}\right]
$$

and $\Lambda$ is a diagonal matrix with the corresponding eigenvalues. $D$ is the length of the line.

The detailed configuration of the considered transmission line (in Fig. 1) is presented below. The applied parameter values are typical values, which vary slightly for the different minor and major sections along the actual connection.

Each cable has six parts (Fig. 7): conductive core with stranded copper wires, semi-conductive layer, XLPE insulation layer, semi-conductive layer, conductive screen layer, and PE outer sheath layer.

Fig. 8-10 show details of trench types, cable joints, and tower configurations. Tables II to IV contain information on the circuit design as being applied in the simulation.

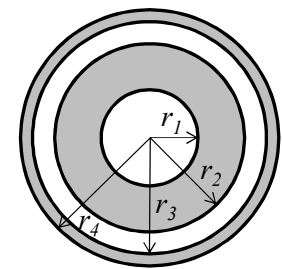

Fig. 7. Four equivalent cable parts derived from the six actual parts [11]: $r_{1}$ : core conductor, $r_{1}-r_{2}$ : insulation, $r_{2}-r_{3}$ : earth screen, $r_{3}-r_{4}$ : outer sheath.

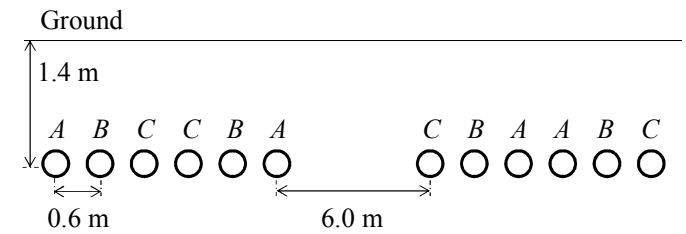

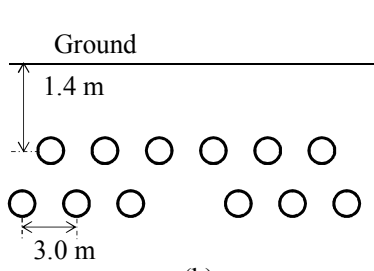

(b) (a)

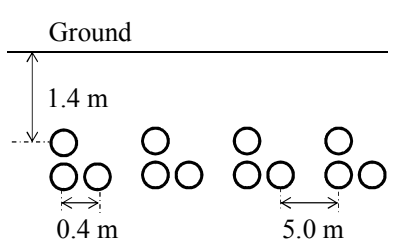

(c)

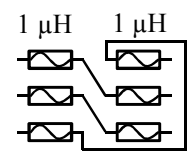

(a)

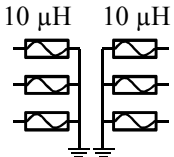

(b)
Fig. 9. Cable joints connecting the screen layers: cross-bonding joint (a); straight through joint (b). This model with values is taken from [11].

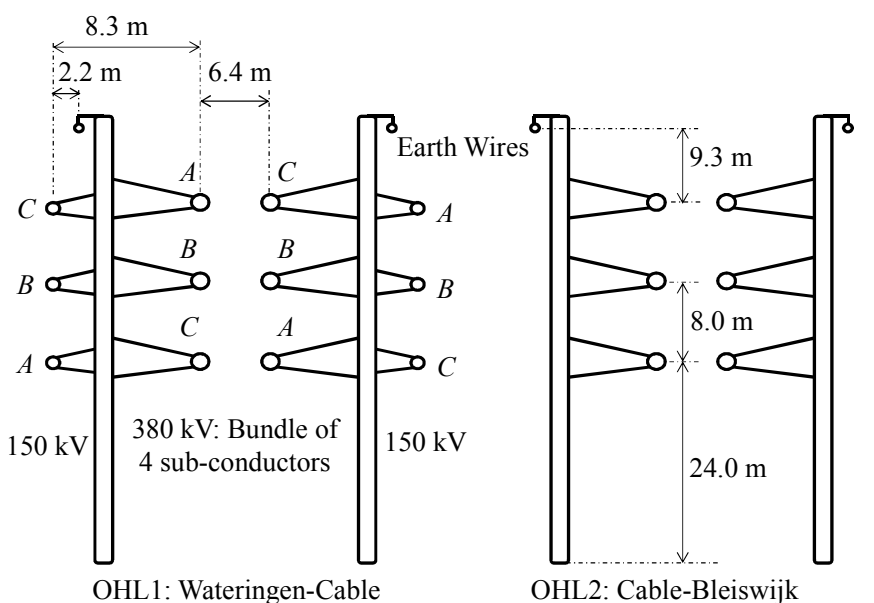

Fig. 10. Configuration of OHL1 and OHL2 pylons.

TABLE II

PARAMETERS FOR CABLE CROSS-SECTIONAL MOdel (FIG. 7)

\begin{tabular}{|c|c|c|c|}
\hline & Radius $(\mathrm{mm})$ & Resistivity $(\Omega \mathrm{m})$ & Relative Permittivity \\
\hline$r_{1}$ & 30.7 & $2.0 \times 10^{-8}$ & - \\
\hline$r_{2}$ & 60.4 & - & 2.7 \\
\hline$r_{3}$ & 62.8 & $7.3 \times 10^{-8}$ & - \\
\hline$r_{4}$ & 67.9 & - & 2.3 \\
\hline
\end{tabular}

TABLE III

12 MinOR SECTION (MS), OHL1, AND OHL2 APPLIED PARAMETERS

\begin{tabular}{|c|c|c|c|}
\hline & Trench type & Earth resistivity $(\Omega \mathrm{m})$ & Length $(\mathrm{km})$ \\
\hline MS 01 & Open trench & 100 & 0.9 \\
\hline MS 02 & HDD1 & 100 & 1.0 \\
\hline MS 03 & Open trench & 100 & 0.8 \\
\hline MS 04 & HDD1 & 50 & 1.1 \\
\hline MS 05 & Open trench & 50 & 0.9 \\
\hline MS 06 & Open trench & 100 & 0.8 \\
\hline MS 07 & HDD1 & 50 & 0.9 \\
\hline MS 08 & Open trench & 100 & 0.8 \\
\hline MS 09 & HDD1 & 100 & 1.0 \\
\hline MS 10 & HDD1 & 50 & 0.9 \\
\hline MS 11 & Open trench & 50 & 0.8 \\
\hline MS 12 & HDD2 & 50 & 0.9 \\
\hline OHL1 & - & 100 & 4.0 \\
\hline OHL2 & - & 100 & 6.0 \\
\hline
\end{tabular}

TABLE IV

PARAMETERS USED FOR MODELING OHL1 AND OHL2 CONDUCTORS

\begin{tabular}{|c|c|c|}
\hline Lines & Radius $(\mathrm{mm})$ & Resistivity $(\Omega \mathrm{m})$ \\
\hline $380 \mathrm{kV}$ & $231.3^{\mathrm{a}}$ & $2.1 \times 10^{-6 \mathrm{a}}$ \\
\hline $150 \mathrm{kV}$ & 16.2 & $4.0 \times 10^{-8}$ \\
\hline Earth wires & 10.9 & $4.8 \times 10^{-8}$ \\
\hline
\end{tabular}

${ }^{\mathrm{a}}$ Equivalent conductor to a bundle of four conductors.

Fig. 8. Three trench types in applied cable system: open trench (a); horizontal directional drilling (HDD1, b), and (HDD2, c). 


\section{REFERENCES}

[1] L.L. Grigsby, The Electric Power Engineering Handbook, CRC Press, IEEE Press, 2001, p. 8-44.

[2] L. van der Sluis, Transients in Power Systems, Wiley, 2001, pp. 22-30.

[3] H. W. Dommel. Electromagnetic Transients Program: Reference Manual: (EMTP theory book). Bonneville Power Administration, 1986.

[4] Manitoba HVDC Research Centre Inc. EMTDC User's Guide, volume 4.7, fifth printing. February 2010.

[5] L. Wu, P.A.A.F. Wouters, and E.F. Steennis. "Frequency Domain Transient Analysis of Resonant Behavior for Different HV Overhead Line and Underground Cable Configurations," unpublished.

[6] L. Wu, P.A.A.F. Wouters, and E.F. Steennis. "Frequency-Domain Analysis of Transients in Mixed Overhead Line-Cable Connection," unpublished.
[7] L. Wu, P.A.A.F. Wouters, and E.F. Steennis. "Model of a double circuit with parallel cables for each phase in a HV cable connection," Power System Technology (POWERCON), 2012 IEEE International Conference on, vol., no., pp.1-5, Oct. 30 2012-Nov. 22012

[8] A. Greenwood, Electrical Transients in Power Systems, $2^{\text {nd }}$ ed., John Wiley \& Sons, Inc., 1991, pp.6-9.

[9] J.C. Das, Power System Analysis: Short-Circuit Load Flow and Harmonics, CRC, 2002, pp. 151-152.

[10] D. J. Higham, N. J. Higham, MATLAB guide, Society for Industrial and Applied Mathematics, 2005, pp. 297 - 305.

[11] U.S. Gudmundsdottir, B. Gustavsen, C. L. Bak, and W. Wiechowski. "Field test and simulation of a 400-kV cross-bonded cable system," IEEE Trans. Power Delivery, 26(3):1403 -1410, July 2011. 